\title{
Dissecting the Mechanisms Underlying Unusually Successful Human Health Span and Life Span
}

\author{
Sofiya Milman ${ }^{1,2}$ and Nir Barzilai ${ }^{1,2,3}$ \\ ${ }^{1}$ Department of Medicine, Division of Endocrinology, Albert Einstein College of Medicine, \\ New York, New York 10461 \\ ${ }^{2}$ Institute for Aging Research, Albert Einstein College of Medicine, New York, New York 10461 \\ ${ }^{3}$ Department of Genetics, Albert Einstein College of Medicine, Bronx, New York 10461 \\ Correspondence: nir.barzilai@einstein.yu.edu
}

Humans age at different rates and families with exceptional survival provide the opportunity to understand why some people age slower than others. Unique features exhibited by centenarians include a family history of longevity, compression of morbidity with resultant extension of health span, and biomarkers such as low-circulating insulin-like growth factor 1 (IGF-1) and elevated high-density lipoprotein (HDL) cholesterol levels. Given the rarity of the centenarian phenotype, it has not been surprising that the use of discovery methods that relied on common population single nucleotide polymorphisms (SNPs) to unlock the genetic determinants of exceptional longevity have not yielded significant results. Conversely, gene sequencing has resulted in discoveries of functional gene variants that support several of the centenarian phenotypes. These discoveries have led to the strategic developments of drugs that may delay aging and prolong health span.

\section{THE RATIONALE FOR STUDYING HUMAN EXCEPTIONAL LONGEVITY}

$T^{\text {he }}$ he United States government annually publishes a report on the rate of death from individual diseases, stratified by age groups. What's striking about these reports is that the rate of death increases logarithmically with advancing age for all diseases associated with aging, including heart disease, cancer, stroke, diabetes mellitus type 2 (T2DM), and Alzheimer's disease (AD) (Fig. 1). This shows that aging is a major risk factor that all of these age-related diseases have in common. To put these statistics in perspective, elevated low-density lipoprotein (LDL) cholesterol level, which is one of the best known and aggressively treated risk factors for heart disease, the most common cause of death among older adults, is associated with a threefold increase in the risk for heart disease. However, advancing the age from 30 years to 80 years raises the rate of death from each of the agerelated diseases by as much as 100- to 1000 fold. If we accept the notion that aging is the common and major risk factor for all age-related diseases, then we conclude that unless aging

Editors: S. Jay Olshansky, George M. Martin, and James L. Kirkland

Additional Perspectives on Aging available at www.perspectivesinmedicine.org

Copyright (C) 2016 Cold Spring Harbor Laboratory Press; all rights reserved; doi: 10.1101/cshperspect.a025098

Cite this article as Cold Spring Harb Perspect Med 2016;6:a025098 
S. Milman and N. Barzilai

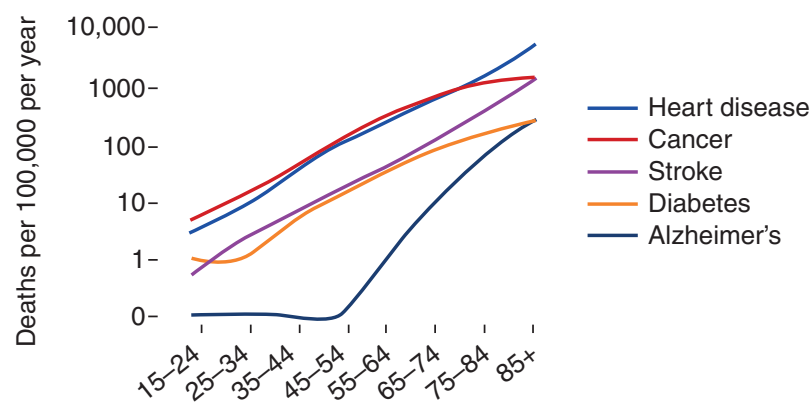

Figure 1. Rate of death per 100,000 people per year for age-related diseases, stratified by age groups ( from Health, United States, 2014, www.cdc.gov/nchs/hus.htm).

itself is delayed our best attempts at preventing each disease individually will result in exchanging one disease for another. The return for curing individual diseases is small. For example, statistical models project that delaying cancer would result in an increase of only $0.8 \%$ in the population of older adults over a 50 -year period, whereas delaying aging would lead to an increase of $\sim 7 \%$ in the population, with most of these individuals being free of disability (Goldman et al. 2013). Furthermore, this delay in aging would yield $\sim \$ 7.1$ trillion in social benefit to the population (Goldman et al. 2013).

When thinking about aging, it is important to recognize that chronological and biological age are not the same. It is well recognized by all that some individuals appear younger than their chronological age, whereas others appear older. This observation highlights an opportunity for scientific discovery that until recently has been missed, that is, to try to understand the biology of why some age faster while others age slower. At one extreme of the spectrum of the rate of aging are rare segmental progeroid syndromes that are thought to accelerate various aging phenotypes. The responsible gene mutations have suggested genomic instability as an important mechanism of aging (Martin 2005). More recently, scientists have become interested in studying people with exceptional longevity, which are located at the other end of the rate of aging spectrum, in an effort to discover the genetic and biological determinants of delayed aging.

Centenarians are a unique group of individuals that constitute an example of delayed aging.
This delay in aging can only be accomplished if it results in the extension of disease-free survival and, indeed, this appears to be the case in many centenarians. Analyses from the New England Centenarian Study (Andersen et al. 2012), the Long Life Family Study (LLFS) (Sebastiani et al. 2013), and the Longevity Genes Program (Ismail 2014) have provided evidence that individuals with exceptional longevity manifest compression of morbidity, meaning that they spend a smaller percentage of their life being ill, and, as a result, their health span approximates their life span. These studies revealed significant delay in the ages of onset for most age-related diseases among individuals with exceptional longevity, including hypertension, cardiovascular disease (CVD), cancer, T2DM, stroke, osteoporosis, and AD. Thus, not only do centenarians live longer, they live healthier. Although a large proportion of centenarians delay or escape from age-related diseases altogether (Evans et al. 2014), a number of individuals achieve exceptional longevity despite having developed one or several of these diseases (Andersen et al. 2012; Ailshire et al. 2015). This suggests that these people likely possess protective factors that allow them to be resilient and survive despite health ailments.

The inherent differences between chronological and biological age, and between the diverse rates of aging, offer scientists opportunities to study the variations in the biology and genetics among these different groups. As exemplified in the literature, several mechanisms have already been identified that can delay aging in a variety of animal models. Investigating 
whether these same mechanisms apply to humans with exceptional longevity serves to validate these discoveries as important for human aging. Furthermore, studies are underway for discovery of age-delaying mechanisms that are specific to humans by using centenarian populations. The rationale for studying centenarians is that they are the "poster children" for what we are ultimately trying to achieve-extension of health span and not merely life span.

\section{THE EVIDENCE THAT LONGEVITY IS INHERITED}

Demographers and epidemiologists have attributed $\sim 15 \%-30 \%$ of the variation in life span to heritable factors. Several studies have found positive correlations between the life spans of the parents and their biological children (Atzmon et al. 2004; Schoenmaker et al. 2006; Westendorp et al. 2009). However, the advances of modern medicine that include preventive measures and treatments, have extended the life spans of the newer generations beyond what would have been predicted based on their inheritance. Thus, offspring whose parents died from CVD resulting from hereditary hyperlipidemia, can now enjoy an extension of their life span through treatment with cholesterol-lowering medications and interventions such as coronary artery bypass graft surgery or revascularization of coronary arteries with angioplasty. Despite these significant medical advances, achievement of exceptional longevity remains a rare occurrence. Yet, exceptional longevity clusters in families point to a strong relationship between genetics and longevity.

Data suggests that the offspring of parents who achieved a life span of at least 70 years have a much greater probability of living longer compared with the offspring of parents with shorter life spans, with this association becoming stronger as the parental life span lengthens (Gavrilov et al. 2001). This relationship is even more pronounced in families with exceptional longevity. Siblings of centenarians have been shown to be $\sim 4-5$ times more likely to achieve longevity, with male siblings being 17 times more likely to become centenarians themselves (Perls et al. 1998, 2002). The parents of centenarians were found to be seven times more likely to have survived to age 90 and beyond, compared with parents of those with the usual life span (Atzmon et al. 2004). Even if genetics account for smaller differences observed in the rate of aging, identification of these genes is important for planning strategies that can delay the aging process. Furthermore, because exceptional longevity is heritable, studying the families of centenarians to identify genetic determinants of exceptional longevity offers great promise for discovery.

Familial longevity is likely mediated through protection from age-related diseases, which is inherited by the offspring from their parents. Centenarians and their offspring have a lower prevalence and later age of onset of heart disease, stroke, hypertension, T2DM, AD, and cancer (Anderson et al. 1991; Atzmon et al. 2004; Adams et al. 2008; Lipton et al. 2010; AltmannSchneider et al. 2012). This heritable protection from disease has also been shown in several large studies. A prospective population-based study found that the incidence of $\mathrm{AD}$ was $43 \%$ lower in offspring of parents with exceptional longevity compared with offspring of parents with more usual life spans over a 23-year follow-up (Lipton et al. 2010). A similar association was also found in a study conducted in a population whose parents achieved more modest longevity. In a secondary analysis of the Diabetes Prevention Program (DPP), a large clinical trial designed to compare strategies for T2DM prevention in individuals at high risk for T2DM, parental longevity was associated with a delay in the incidence of T2DM in the offspring, with the children of parents with longest life spans experiencing the greatest delay in disease onset (Florez et al. 2011). The effect of parental life span on diabetes prevention was found to be just as strong as the effect of metformin, an antidiabetic drug used in this study (Florez et al. 2011). These results show that extended parental life span is strongly associated with better health outcomes in the offspring, even in populations who achieve less extreme degrees of longevity. 
Although environmental influences may have a significant effect on health and life span in the general population, this does not seem to be the case in centenarians. A study that compared individuals with exceptional longevity to their contemporaries who did not achieve longevity found that centenarians were as likely as their shorter-lived peers to have been overweight or obese (Rajpathak et al. 2011). Furthermore, the proportion of centenarians who smoked, consumed alcohol daily, had not participated in regular physical activity, or had not followed a low-calorie diet throughout their middle age was similar to that among their peers from the same birth cohort. In fact, as many as $60 \%$ of male and $30 \%$ of female centenarians had been smokers (Rajpathak et al. 2011). Thus, the centenarians had not engaged in a healthier lifestyle compared with their peers. This supports the notion that people with exceptional longevity possess genomic factors that protect them from the environmental influences that may be detrimental to health.

\section{GENETICS OF EXCEPTIONAL LONGEVITY}

For more than a decade, centenarian populations of diverse Americans, as well as ethnically homogeneous populations of Mormons, Ashkenazi Jews (AJs), Icelandics, Okinawan Japanese, Italians, Irish, and Dutch, among others, have served as cohorts for studies to identify longevity genes or longevity-associated biological pathways. These studies relied on candidate genes and genome-wide association studies (GWAS) that included genotyping of large populations. One of the strengths of GWAS compared with the candidate gene approach is that these studies are unbiased. Their results may provide insights into novel mechanisms of longevity. Several research groups have conducted GWAS for longevity (Beekman et al. 2010; Sebastiani et al. 2012), yet none yielded significant results after appropriate statistical corrections for multiple comparisons were applied. One exception was the finding of the APOE2 genotype, although its identification may have been the result of ascertainment bias, because individuals with the APOE4 allele, who are at higher risk for developing Alzheimer's dementia, are less likely to be recruited into population studies (Nebel et al. 2011).

There are several explanations for these disappointing results. First, relying on common genetic variants that occur at frequencies from $5 \%$ to $49 \%$ in the population to study such a rare event as exceptional longevity (one that occurs at a rate of $1 / 6000-1 / 10,000$ in the general population) may result in missing the rarer longevity-associated genotypes. This also underscores the need for exon or whole-genome sequencing to discover rare mutations. Second, applying GWAS to genetically diverse populations requires a very large study cohort to account for genomic diversity and to identify relatively rare genetic variants. Thus, most studies have lacked sufficient power for such discoveries.

Following this logic, it is not surprising that many important genetic discoveries were made in populations that show comparatively small levels of genetic diversity. One such example is the Icelandic population, which originated from a small number of founders and expanded to $\sim 500,000$ people. Others include the Amish and AJs, a larger population (Barzilai et al. 2003; Atzmon et al. 2008, 2009b, 2010; Suh et al. 2008). The advantage of studying a genetically homogeneous population was exemplified by a recent study, which showed that the addition of each AJ subject contributed 20 times more genetic variability to the cohort as compared with adding a European subject to a cohort of European origin of identical sample size (Carmi et al. 2014).

There are several ways in which genetically similar populations can contribute to genetic and biological discovery. One is if the population has a higher frequency of carriers of a particular genotype and its associated phenotype caused by the founder effect, as is the case with breast cancer caused by mutations in the $B R C A$ genes among AJ women. Another is that single nucleotide polymorphisms (SNPs) that are novel or rare in the general population will occur at higher frequencies in a homogenous population. This will result in the associated rare phenotype, such as longevity, to be more amenable to withstand the rigorous statistical analysis that is performed on genetic data. 
Third, many SNPs that are statistically significant, but below the threshold for GWAS, may still be relevant. Last, it is possible that numerous SNPs contribute in combination to the phenotype. Indeed, Sebastiani et al. (2012) have identified 281 SNPs that can distinguish centenarians from controls.

Although discovery of longevity-associated genes has been met with several challenges, many genes have been identified that are associated with risk for CVD, AD, T2DM, and other age-related diseases. One attractive hypothesis has been that centenarians lack these disease-associated genes, thus being protected by a more "perfect genome." However, it has become clear from GWAS that centenarians harbor as many disease-associated genotypes as controls. Furthermore, a whole-genome sequence analysis of 44 centenarians revealed that this group carried a total of 227 autosomal and $7 \mathrm{X}$-chromosome coding single nucleotide variants (SNVs) that are likely to cause disease according to the ClinVar database (Freudenberg-Hua et al. 2014). Among these are variants associated with Parkinson's disease, AD, neurodegenerative diseases, neoplastic, and cardiac diseases. Despite $>95$ years of exposure to these risky genotypes, none of the centenarians showed any of the diseases for which they were genetic carriers. These observations led to the conclusion that there are longevity-associated protective genotypes in centenarians that delay aging or specifically protect against the manifestation of age-related diseases.

Although the GWAS approach did not prove to be particularly helpful in identifying longevity genes, some success stories have emerged through the application of the candidate gene approach. Several genes were selected for investigation because they were previously implicated in aging, and SNPs within these genes were suggested to be linked with longevity. These included PON1 (Bonafe et al. 2002; Rea et al. 2004; Franceschi et al. 2005; Marchegiani et al. 2006; Tan et al. 2006), insulin-like growth factor 1 (IGF-1) (Bonafe et al. 2003; Kojima et al. 2004; van Heemst et al. 2005), PAPR-1, cytokine genes, genes that code for enzymatic antioxidants such as superoxide dismutases (Andersen et al. 1998;
Mecocci et al. 2000), and components of lipid metabolism (Barzilai et al. 2006; Vergani et al. 2006). Other genes that have been implicated in human aging, and not only longevity, are updated on the Aging Gene Database (see genomics .senescence.info/genes).

However, not all discoveries resulted in improved understanding of the biology of aging. One of the most notable discoveries of a longevity-associated gene, which has been validated by numerous research groups, is the FOXO3a genotype. As summarized by Kahn (2014), the FOXO3a genotypes are rather common, the identified SNPs within the gene localize to intronic or noncoding regions, and despite sequencing of the whole gene by several groups, no functional mutations have thus far been identified in the regions of the gene that would predict altered protein function. Furthermore, assays of cells with the FOXO3a genotype variants also have not been, thus far, associated with functional changes. Finally, no identifiable phenotype has yet been linked with these FOXO3a genotypes and they have not been related to risk or protection from disease. In fact, a panel of experts did not agree on whether a drug that displaces FOXO3a from the nucleus to the cytoplasm would induce longevity or shorten the life span (Monsalve and Olmos 2011). The example of FOXO3a shows that even a validated genotype does not always translate into better understanding of the biology of longevity.

There are also other challenges that researchers face studying longevity. In addition to the usual problems and pitfalls of association studies, particularly in the new age of "big data" brought on by whole-genome sequencing (Lawrence et al. 2005), there is another problem that is particular to longevity studies - that of identifying appropriate controls for a cohort of exceptionally long-lived individuals. This has been a challenge because the ideal controls, individuals of the same birth cohort as the centenarians but who have not achieved exceptional longevity, are all deceased. One approach to overcome this challenge has been to rely on the innovative experimental design in which the progeny of centenarians, who have inherited about half of their genome from the centenarian 
parent, are compared with their spouses who do not have a parental history of longevity and thus can serve as matched controls (Barzilai et al. 2001).

\section{GENOMIC DISCOVERIES AND MECHANISMS FOR EXCEPTIONAL LONGEVITY}

The Longevity Genes Project (LGP) and LonGenity are studies that include families of AJs with exceptional longevity. Because longevity carries a substantial genetic component, these studies conduct genomic and detailed phenotype analyses in the families with exceptional longevity in an effort to determine the functions of genes of interest. Using the candidate gene approach in this AJ cohort, several favorable homozygous genotypes were identified in multiple genes, which were associated with unique biological phenotypes.

The cholesterol ester transfer protein (CETP) gene codon 405 isoleucine to valine variant was associated with low levels of plasma CETP, high levels of high-density lipoprotein (HDL) cholesterol, and large lipoprotein particle size. This genotype was also shown to be protective against cognitive decline and $\mathrm{AD}$ in an independent diverse population (Sanders et al. 2010). This same genotype was validated by another research group in an Italian population (Vergani et al. 2006). Three other genotypes in the CETP gene were also found to be significantly associated with longevity in the LLFS study. Although none of the other studies have confirmed these findings, it is important to keep in mind that a particular SNP may not show a similar phenotype in all populations. Therefore, the biological phenotype itself should be tested for association with longevity rather than a particular SNP that may have differential expression in varying populations. Further complicating matters is the possibility that the gene with the significant action may be in linkage disequilibrium with the SNP and that there may be genetic variations at that associated locus.

Another lipid-related genotype, homozygosity for the apolipoprotein C-3 (APOC-3)$641 \mathrm{C}$ allele was also associated with exceptional longevity in AJs (Atzmon et al. 2006). It too showed a unique lipid phenotype and low levels of plasma APOC-3 (Atzmon et al. 2006). In a striking example of validation, carriers of a different APOC3 genotype in a homogenous Pennsylvania Amish population also showed low APOC-3 levels, a favorable lipid phenotype, better arterial health score, and enhanced longevity (Pollin et al. 2008). These findings show the power of discovery in selected genetically homogeneous populations. The APOC-3 genotype was also identified to be related to exceptional longevity in the LLFS, but the phenotype associated with this SNP has not yet been revealed.

$A D I P O Q$ is another longevity-associated genotype. Adiponectin is a fat-derived peptide with powerful effects on lipids and metabolism. A deletion at +2019 in the adiponectin (ADIPOQ) gene was associated in the AJ cohorts with longevity, which was also related to a phenotype of high adiponectin levels, independent of fat mass (Atzmon et al. 2008).

A longevity-associated genotype whose discovery has already made an impact on clinical practice is that of the thyroid stimulating hormone receptor (TSHR) (Atzmon et al. 2009a,b). The metabolic rate theory of aging suggests that, in nature, there exists an inverse relationship between basal metabolic rate and aging, with several hypothyroid mammalian models showing longer life span. Centenarians have higher plasma thyroid stimulating hormone (TSH) levels, although they are not hypothyroid, and their offspring also show this phenotype with significant hereditability (Atzmon et al. 2009a; Rozing et al. 2010). These clinical features have been supported by a National Health and Nutrition Examination Survey (NHANES III) conducted across the United States and led to the recommendation to not supplement older adults with mild elevations in TSH with thyroid hormone (Tabatabaie and Surks 2013).

In nature, disruption of the growth hormone $(\mathrm{GH}) / \mathrm{IGF}-1$ action has led to extension of life span. Spontaneous and experimentally induced partial disruptions of the GH/IGF-1 pathway, including genetic alterations, are associated with a small body size (dwarfism) across 
species (Brown-Borg et al. 1996). Thus, small dogs have longer life spans than large dogs (Samaras and Elrick 2002). Models of IGF-1 deficiency show numerous indices of delayed aging, including enhanced stress resistance and a major increase in life span (Kenyon et al. 1993; Brown-Borg et al. 1996). On the other hand, reduced levels of IGF-1 in humans, while protective against cancer, have been linked with higher risk for CVD and diabetes (Sandhu et al. 2002; Burgers et al. 2011), suggesting a more complex physiological role for IGF-1 in humans. Several SNPs in genes within the insulin/IGF-1-signaling pathway have been associated with and validated in exceptional longevity, but, for the most part, no specific phenotype related to these SNPs has been identified (Pawlikowska et al. 2009). An exception to this has been the identification of a functional IGF-1 receptor $(I G F-1 R)$ gene mutation discovered after sequencing the $I G F-1$ and $I G F-1 R$ genes of centenarians (Suh et al. 2008). Heterozygous mutations in the IGF-1R gene have been overrepresented among centenarians compared with the controls without familial longevity and have been associated with high-serum IGF-1 levels in the setting of reduced activity of the $I G F-1 R$, as measured in transformed lymphocytes (Tazearslan et al. 2011). Partial IGF-1 resistance conferred by these longevity-associated $I G F-1 R$ genotypes was confirmed in a study conducted on wild-type cells transformed with the mutant genes (Tazearslan et al. 2011). A particular IGF-1R genotype was also associated with longevity in the LLFS; however, its associated phenotype has not yet been defined.

Another example that highlights the importance of GH/IGF-1 signaling in extended health span comes from a population of Laron Dwarfs, who are carriers of a rare mutation in the $\mathrm{GH}$ receptor $(G H R)$ gene that results in GHR deficiency. A group with this genotype was studied in Ecuador and appears to have a negligible prevalence of type 2 diabetes mellitus and cancer (Guevara-Aguirre et al. 2011). Although they did not live long, clearly they have been protected from major age-related diseases.

Finally, among females with exceptional longevity, those with IGF-1 levels below the
Mechanisms for Exceptional Longevity in Humans

median exhibited significantly longer survival compared with those with levels above the median (Fig. 2) (Milman et al. 2014). However, this relationship between IGF-1 levels and survival was not observed in males with exceptional longevity. On the other hand, among males and females who achieved longevity and had a history of cancer, lower IGF- 1 levels predicted longer survival (Milman et al. 2014). Thus, low IGF-1 levels predict life expectancy in exceptionally long-lived individuals, supporting the role of the GH/IGF-1 pathway in exceptional longevity.

Interest in telomeres and their association with aging led to significant research efforts aimed at identifying the role of telomere length in exceptional longevity. Telomere length or mass assessment showed that centenarians have longer telomeres, that this length is inherited in their offspring, and is associated with decreased incidence of the metabolic syndrome (MS), T2DM, and cognitive decline (Atzmon et al. 2010). This longevity-associated telomere phenotype has also been related to a genetic "fingerprint" in the telomerase genes in centenarians (Atzmon et al. 2010).

Other genomic mechanisms, no doubt, also contribute to aging, including epigenomic variations. Sirtuins, resveratrol, and other specific activators have been used to induce histone deacetylation and activation of the SIRT1 gene, thereby resulting in longevity in a variety of animal models and in high-fat fed mice. However, no significant association between SIRT1 genotypes and longevity has been reported in humans thus far (Han et al. 2014). Methylation patterns have been noted to change with aging and may affect the transcribed DNA. Initial studies have shown significant differences in methylation patterns between centenarians and younger controls, with several groups currently pursuing this line of research. Finally, longevityassociated microRNAs have been identified, but their effects still need to be determined (Gombar et al. 2012).

\section{EXCEPTIONAL LONGEVITY LEADING TO AGE-DELAYING DRUGS}

The goal of longevity research is to identify pathways that are relevant to human aging and 


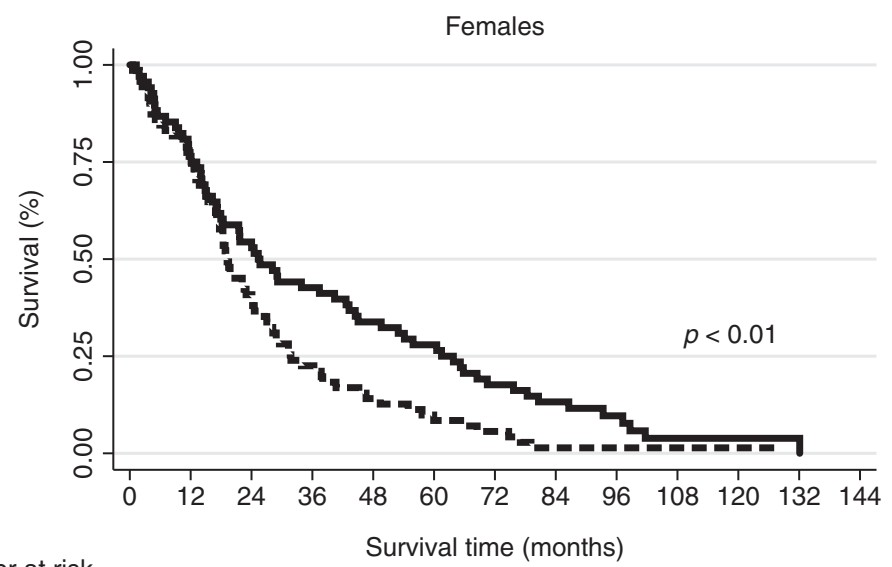

Number at risk

Survival time (months)

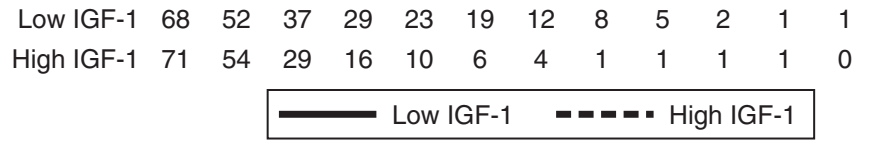

Figure 2. Kaplan-Meier survival curves for females with IGF-1 levels above and below the median. (From Milman et al. 2014; adapted, with permission.)

to develop drugs that will delay aging by targeting these pathways. Longevity and extension of healthy life span have been achieved in models via a variety of genetic manipulations, drugs, and environmental influences, thereby providing the preclinical foundation needed to proceed to drug development. The main obstacle facing the development of drugs for the treatment of aging is the fact that the U.S. Food and Drug Administration (FDA) does not consider aging as a preventable condition. Even if there would be a popular demand for drugs that delay aging, the pharmaceutical industry would not develop drugs that will not be reimbursed by health insurance companies. The same was true for hypertension, until studies showed that lowering blood pressure prevented CVD, including strokes.

The pharmaceutical industry has relied on genetic discoveries made in longevity studies, as well as other studies, to identify individuals who have naturally occurring genetic variants or mutations that confer desirable phenotypes. The goals for pharmaceutical development is to create drugs whose actions would mimic those of the favorable genetic variants. Observing the carriers of these genetic variants for any detrimental health effects informs drug makers of any potential side effects that may arise from a drug that targets the desired pathway. For example, the observation that centenarians are enriched with a unique CETP genotype that exposes them to a lifetime of lower CETP levels that is also associated with high HDL level and large lipoprotein particle size, suggests that decreased CETP function is safe (Barzilai et al. 2003). In fact, a CETP inhibitor is currently being tested in a phase 3 trial by a leading pharmaceutical company (Cannon et al. 2010). Similar observations were made about the APOC-3 protein, and an APOC-3 inhibitor is also being tested in a phase 3 trial by another pharmaceutical company (Graham et al. 2013; Lee et al. 2013).

Another class of agents whose actions on aging may be predicted through longevity research are monoclonal antibodies directed against the IGF-1 receptor. These were initially developed by several pharmaceutical industries as antineoplastic therapies; however, they were not successful at treating cancer because of a significant degree of mutagenesis within cancer cells that eventually made them resistant to these drugs. Nonetheless, these compounds are available for 
preclinical testing in aging research. Similarly, the GH/IGF-1 pathway, which may be important for human aging, can be targeted by the GHR antagonist that is currently in clinical use for the treatment of acromegaly, a condition of GH excess (Kopchick 2003). Although the above-mentioned therapeutics are not presently being developed for longevity, these drugs may be tested in the future for the indication of delaying aging and age-associated diseases.

Other drugs may target aging more specifically, although they are in clinical use for other indications. One example is a class of drugs that inhibit the mammalian target of rapamycin (mTOR) enzyme. These drugs are primarily used as immune modulators post organ transplantation, but recently also have been shown to increase the immune response to vaccinations in the elderly (Mannick et al. 2014), thereby demonstrating their potential utility in the treatment of health conditions associated with aging.

Another drug of interest is metformin, the first line drug treatment for T2DM. Several research groups tested the effect of metformin on aging and showed that it caused extension in life span and health span in many rodent models (Anisimov et al. 2008, 2010, 2011; Smith et al. 2010; Martin-Montalvo et al. 2013). Metformin also extended the life span of nematodes ( $\mathrm{Ca}$ breiro et al. 2013), suggesting that its action is mediated via an evolutionary conserved mechanism. Numerous investigators looked at the potential antiaging effects of this drug in populations treated with metformin for T2DM. The large United Kingdom Prospective Diabetes Study (UKPDS) convincingly showed that metformin reduced the incidence of CVD (Holman et al. 2008; Anfossi et al. 2010). This finding has been validated and reproduced by other studies and meta-analysis (Johnson et al. 2005; Lamanna et al. 2011; Roumie et al. 2012; Hong et al. 2013; Whittington et al. 2013). In addition, a number of studies suggested that metformin use is associated with a decreased incidence of cancer (Libby et al. 2009; Landman et al. 2010; Lee et al. 2011; Monami et al. 2011; Tseng 2012), with many animal and cell models demonstrating the inhibitory effects of metformin on tumorigenesis (Seibel et al. 2008;
Mechanisms for Exceptional Longevity in Humans

Tosca et al. 2010; Liu et al. 2011; Salani et al. 2012; Anisimov and Bartke 2013; Karnevi et al. 2013; Quinn et al. 2013). The proposed mechanisms of action for metformin's effect on inhibiting tumorigenesis include decrease in insulin production and its action, decrease in IGF-1 signaling, and AMP-activated protein kinase (AMPK) activation.

In the future, other compounds discovered to be important for longevity may be developed into drugs. For example, the level of humanin, a mitochondrial-derived peptide, decreases with aging but has been shown to increase up to threefold in the offspring of centenarians $(\mathrm{Mu}-$ zumdar et al. 2009), thus making it an attractive candidate for drug development.

\section{CONCLUDING REMARKS}

This article shows that, via the use of biologic and genetic experimental methods, scientists can determine why some people age more slowly or more rapidly than others. Such discoveries in humans, as opposed to those in other animal models, have the advantage of being directly relevant to human longevity and can be relied on by pharmaceutical developers looking to establish the safety of drugs whose actions mimic the function of the genetic variants found in centenarians. Thus it follows that if functional mutations or SNPs that are more common in centenarians are also deemed safe in that population, then drugs that mimic the desired actions are worth developing. This kind of drug development should result in unique drugs that target not only specific diseases but also aging. The barrier for development of drugs that target aging is that, at present, aging is not an indication for treatment by the FDA. There is an urgent need to change this paradigm to accelerate drug development and realize the longevity dividend.

\section{ACKNOWLEDGMENTS}

S.M. is supported by the National Center for Advancing Translational Sciences of the National Institutes of Health under Award Number KL2TR001071. N.B. is supported by Grants 
from the National Institutes of Health (NIH) (P01AG021654), The Nathan Shock Center of Excellence for the Biology of Aging (P30AG038072), the Glenn Center for the Biology of Human Aging (Paul Glenn Foundation for Medical Research), NIH R37 AG18381 (Barzilai Merit Award), and NIH/NIA 1 R01AG044829. The content is solely the responsibility of the authors and does not necessary represent the official views of the NIH.

\section{REFERENCES}

Adams ER, Nolan VG, Andersen SL, Perls TT, Terry DF. 2008. Centenarian offspring: Start healthier and stay healthier. J Am Geriatr Soc 56: 2089-2092.

Ailshire JA, Beltran-Sanchez H, Crimmins EM. 2015. Becoming centenarians: Disease and functioning trajectories of older US Adults as they survive to 100. J Gerontol A Biol Sci Med Sci 70: 193-201.

Altmann-Schneider I, van der Grond J, Slagboom PE, Westendorp RG, Maier AB, van Buchem MA, de Craen AJ. 2012. Lower susceptibility to cerebral small vessel disease in human familial longevity: The Leiden Longevity Study. Stroke 44: 9-14.

Andersen HR, Jeune B, Nybo H, Nielsen JB, Andersen-Ranberg K, Grandjean P. 1998. Low activity of superoxide dismutase and high activity of glutathione reductase in erythrocytes from centenarians. Age Ageing 27: 643-648.

Andersen SL, Sebastiani P, Dworkis DA, Feldman L, Perls TT. 2012. Health span approximates life span among many supercentenarians: Compression of morbidity at the approximate limit of life span. J Gerontol A Biol Sci Med Sci 67: 395-405.

Anderson KM, Odell PM, Wilson PW, Kannel WB. 1991. Cardiovascular disease risk profiles. Am Heart J 121: 293-298.

Anfossi G, Russo I, Bonomo K, Trovati M. 2010. The cardiovascular effects of metformin: Further reasons to consider an old drug as a cornerstone in the therapy of type 2 diabetes mellitus. Curr Vasc Pharmacol 8: 327-337.

Anisimov VN, Bartke A. 2013. The key role of growth hormone-insulin-IGF-1 signaling in aging and cancer. Crit Rev Oncol Hematol 87: 201-223.

Anisimov VN, Berstein LM, Egormin PA, Piskunova TS, Popovich IG, Zabezhinski MA, Tyndyk ML, Yurova MV, Kovalenko IG, Poroshina TE, et al. 2008. Metformin slows down aging and extends life span of female SHR mice. Cell Cycle 7: 2769-2773.

Anisimov VN, Egormin PA, Piskunova TS, Popovich IG, Tyndyk ML, Yurova MN, Zabezhinski MA, Anikin IV, Karkach AS, Romanyukha AA. 2010. Metformin extends life span of HER-2/neu transgenic mice and in combination with melatonin inhibits growth of transplantable tumors in vivo. Cell Cycle 9: 188-197.

Anisimov VN, Berstein LM, Popovich IG, Zabezhinski MA, Egormin PA, Piskunova TS, Semenchenko AV, Tyndyk ML, Yurova MN, Kovalenko IG, et al. 2011. If started early in life, metformin treatment increases life span and postpones tumors in female SHR mice. Aging (Albany NY) 3: 148-157.

Atzmon G, Schechter C, Greiner W, Davidson D, Rennert G, Barzilai N. 2004. Clinical phenotype of families with longevity. J Am Geriatr Soc 52: 274-277.

Atzmon G, Rincon M, Schechter CB, Shuldiner AR, Lipton RB, Bergman A, Barzilai N. 2006. Lipoprotein genotype and conserved pathway for exceptional longevity in humans. PLoS Biol 4: el13.

Atzmon G, Pollin TI, Crandall J, Tanner K, Schechter CB, Scherer PE, Rincon M, Siegel G, Katz M, Lipton RB, et al. 2008. Adiponectin levels and genotype: A potential regulator of life span in humans. J Gerontol A Biol Sci Med Sci 63: 447-453.

Atzmon G, Barzilai N, Hollowell JG, Surks MI, Gabriely I. 2009a. Extreme longevity is associated with increased serum thyrotropin. J Clin Endocrinol Metab 94: 12511254.

Atzmon G, Barzilai N, Surks MI, Gabriely I. 2009b. Genetic predisposition to elevated serum thyrotropin is associated with exceptional longevity. J Clin Endocrinol Metab 94: 4768-4775.

Atzmon G, Cho M, Cawthon RM, Budagov T, Katz M, Yang X, Siegel G, Bergman A, Huffman DM, Schechter CB, et al. 2010. Evolution in health and medicine Sackler colloquium: Genetic variation in human telomerase is associated with telomere length in Ashkenazi centenarians. Proc Natl Acad Sci 107: 1710-1717.

Barzilai N, Gabriely I, Gabriely M, Iankowitz N, Sorkin JD. 2001. Offspring of centenarians have a favorable lipid profile. J Am Geriatr Soc 49: 76-79.

Barzilai N, Atzmon G, Schechter C, Schaefer EJ, Cupples AL, Lipton R, Cheng S, Shuldiner AR. 2003. Unique lipoprotein phenotype and genotype associated with exceptional longevity. JAMA 290: 2030-2040.

Barzilai N, Atzmon G, Derby CA, Bauman JM, Lipton RB. 2006. A genotype of exceptional longevity is associated with preservation of cognitive function. Neurology 67: 2170-2175.

Beekman M, Nederstigt C, Suchiman HE, Kremer D, van der Breggen R, Lakenberg N, Alemayehu WG, de Craen AJ, Westendorp RG, Boomsma DI, et al. 2010. Genomewide association study (GWAS)-identified disease risk alleles do not compromise human longevity. Proc Natl Acad Sci 107: 18046-18049.

Bonafe M, Marchegiani F, Cardelli M, Olivieri F, Cavallone L, Giovagnetti S, Pieri C, Marra M, Antonicelli R, Troiano L, et al. 2002. Genetic analysis of paraoxonase (PON1) locus reveals an increased frequency of Arg192 allele in centenarians. Eur J Hum Genet 10: 292-296.

Bonafe M, Barbieri M, Marchegiani F, Olivieri F, Ragno E, Giampieri C, Mugianesi E, Centurelli M, Franceschi C, Paolisso G. 2003. Polymorphic variants of insulin-like growth factor I (IGF-I) receptor and phosphoinositide 3-kinase genes affect IGF-I plasma levels and human longevity: Cues for an evolutionarily conserved mechanism of life span control. J Clin Endocrinol Metab 88: 32993304.

Brown-Borg HM, Borg KE, Meliska CJ, Bartke A. 1996. Dwarf mice and the ageing process. Nature 384: 33. 
Burgers AM, Biermasz NR, Schoones JW, Pereira AM, Renehan AG, Zwahlen M, Egger M, Dekkers OM. 2011. Meta-analysis and dose-response metaregression: Circulating insulin-like growth factor I (IGF-I) and mortality. J Clin Endocrinol Metab 96: 2912-2920.

Cabreiro F, Au C, Leung KY, Vergara-Irigaray N, Cocheme HM, Noori T, Weinkove D, Schuster E, Greene ND, Gems D. 2013. Metformin retards aging in C. elegans by altering microbial folate and methionine metabolism. Cell 153: 228-239.

Cannon CP, Shah S, Dansky HM, Davidson M, Brinton EA, Gotto AM, Stepanavage M, Liu SX, Gibbons P, Ashraf TB, et al. 2010. Safety of anacetrapib in patients with or at high risk for coronary heart disease. $N$ Engl J Med 363 . 2406-2415.

Carmi S, Hui KY, Kochav E, Liu X, Xue J, Grady F, Guha S, Upadhyay K, Ben-Avraham D, Mukherjee S, et al. 2014. Sequencing an Ashkenazi reference panel supports population-targeted personal genomics and illuminates Jewish and European origins. Nat Commun 5: 4835.

Evans CJ, Ho Y, Daveson BA, Hall S, Higginson IJ, Gao W. 2014. Place and cause of death in centenarians: A population-based observational study in England, 2001 to 2010. PLoS Med 11: e1001653.

Florez H, Ma Y, Crandall JP, Perreault L, Marcovina SM, Bray GA, Saudek CD, Barrett-Connor E, Knowler WC. 2011. Parental longevity and diabetes risk in the Diabetes Prevention Program. J Gerontol A Biol Sci Med Sci 66: 1211 1217.

Franceschi C, Olivieri F, Marchegiani F, Cardelli M, Cavallone L, Capri M, Salvioli S, Valensin S, De Benedictis G Di Iorio A, et al. 2005. Genes involved in immune response/inflammation, IGF1/insulin pathway and response to oxidative stress play a major role in the genetics of human longevity: The lesson of centenarians. Mech Ageing Dev 126: 351-361.

Freudenberg-Hua Y, Freudenberg J, Vacic V, Abhyankar A, Emde AK, Ben-Avraham D, Barzilai N, Oschwald D, Christen E, Koppel J, et al. 2014. Disease variants in genomes of 44 centenarians. Mol Genet Genomic Med 2: $438-450$.

Gavrilov L, Gavrilova N, Semyonova V, Evdokushkina G. 2001. Parental age effects on human longevity. In Annual Meeting of the Gerontological Society of America, Chicago, November 15-18.

Goldman DP, Cutler D, Rowe JW, Michaud PC, Sullivan J, Peneva D, Olshansky SJ. 2013. Substantial health and economic returns from delayed aging may warrant a new focus for medical research. Health Aff (Millwood) 32: $1698-1705$.

Gombar S, Jung HJ, Dong F, Calder B, Atzmon G, Barzilai N, Tian XL, Pothof J, Hoeijmakers JH, Campisi J, et al. 2012. Comprehensive microRNA profiling in B-cells of human centenarians by massively parallel sequencing. $B M C \mathrm{Ge}$ nomics 13: 353.

Graham MJ, Lee RG, Bell TA III, Fu W, Mullick AE, Alexander VJ, Singleton W, Viney N, Geary R, Su J, et al. 2013 Antisense oligonucleotide inhibition of apolipoprotein C-III reduces plasma triglycerides in rodents, nonhuman primates, and humans. Circ Res 112: 1479-1490.

Guevara-Aguirre J, Balasubramanian P, Guevara-Aguirre M, Wei M, Madia F, Cheng CW, Hwang D, Martin-Montalvo
Mechanisms for Exceptional Longevity in Humans

A, Saavedra J, Ingles S, et al. 2011. Growth hormone receptor deficiency is associated with a major reduction in pro-aging signaling, cancer, and diabetes in humans. Sci Transl Med 3: 70ra13.

Han J, Atzmon G, Barzilai N, Suh Y. 2014. Genetic variation in Sirtuin 1 (SIRT1) is associated with lipid profiles but not with longevity in Ashkenazi Jews. Transl Res 165: 480-481.

Holman RR, Paul SK, Bethel MA, Matthews DR, Neil HA. 2008. 10-year follow-up of intensive glucose control in type 2 diabetes. N Engl J Med 359: 1577-1589.

Hong J, Zhang Y, Lai S, Lv A, Su Q, Dong Y, Zhou Z, Tang W, Zhao J, Cui L, et al. 2013. Effects of metformin versus glipizide on cardiovascular outcomes in patients with type 2 diabetes and coronary artery disease. Diabetes Care 36: 1304-1311.

Ismail KNL, Sebastiani P, Milman S, Perls TT, Barzilai N. 2014. Individuals with exceptional longevity exhibit increased health span and delayed onset of age-related diseases. In Presidential Poster Session of the American Geriatrics Society Annual Meeting, Orlando, FL, May 15-18.

Johnson JA, Simpson SH, Toth EL, Majumdar SR. 2005. Reduced cardiovascular morbidity and mortality associated with metformin use in subjects with type 2 diabetes. Diabet Med 22: 497-502.

Kahn AJ. 2014. FOXO3 and related transcription factors in development, aging, and exceptional longevity. J Gerontol A Biol Sci Med Sci 70: 421-425.

Karnevi E, Said K, Andersson R, Rosendahl AH. 2013. Metformin-mediated growth inhibition involves suppression of the IGF-I receptor signalling pathway in human pancreatic cancer cells. BMC Cancer 13: 235.

Kenyon C, Chang J, Gensch E, Rudner A, Tabtiang R. 1993. A C. elegans mutant that lives twice as long as wild type. Nature 366: 461-464.

Kojima T, Kamei H, Aizu T, Arai Y, Takayama M, Nakazawa S, Ebihara Y, Inagaki H, Masui Y, Gondo Y, et al. 2004. Association analysis between longevity in the Japanese population and polymorphic variants of genes involved in insulin and insulin-like growth factor 1 signaling pathways. Exp Gerontol 39: 1595-1598.

Kopchick JJ. 2003. Discovery and mechanism of action of pegvisomant. Eur J Endocrinol 148: S21-25.

Lamanna C, Monami M, Marchionni N, Mannucci E. 2011. Effect of metformin on cardiovascular events and mortality: A meta-analysis of randomized clinical trials. $D i-$ abetes Obes Metab 13: 221-228.

Landman GW, Kleefstra N, van Hateren KJ, Groenier KH, Gans RO, Bilo HJ. 2010. Metformin associated with lower cancer mortality in type 2 diabetes: ZODIAC-16. Diabetes Care 33: 322-326.

Lawrence RW, Evans DM, Cardon LR. 2005. Prospects and pitfalls in whole genome association studies. Philos Trans $R$ Soc Lond B Biol Sci 360: 1589-1595.

Lee MS, Hsu CC, Wahlqvist ML, Tsai HN, Chang YH, Huang YC. 2011. Type 2 diabetes increases and metformin reduces total, colorectal, liver and pancreatic cancer incidences in Taiwanese: A representative population prospective cohort study of 800,000 individuals. BMC Cancer 11: 20. 
Lee RG, Crosby J, Baker BF, Graham MJ, Crooke RM. 2013 Antisense technology: An emerging platform for cardiovascular disease therapeutics. J Cardiovasc Transl Res 6: 969-980.

Libby G, Donnelly LA, Donnan PT, Alessi DR, Morris AD, Evans JM. 2009. New users of metformin are at low risk of incident cancer: A cohort study among people with type 2 diabetes. Diabetes Care 32: 1620-1625.

Lipton RB, Hirsch J, Katz MJ, Wang C, Sanders AE, Verghese J, Barzilai N, Derby CA. 2010. Exceptional parental longevity associated with lower risk of Alzheimer's disease and memory decline. J Am Geriatr Soc 58: 1043-1049.

Liu B, Fan Z, Edgerton SM, Yang X, Lind SE, Thor AD. 2011. Potent anti-proliferative effects of metformin on trastuzumab-resistant breast cancer cells via inhibition of erbB2/IGF-1 receptor interactions. Cell Cycle 10: 2959-2966.

Mannick JB, Del Giudice G, Lattanzi M, Valiante NM, Praestgaard J, Huang B, Lonetto MA, Maecker HT, Kovarik J, Carson S, et al. 2014. mTOR inhibition improves immune function in the elderly. Sci Transl Med 6: 268ra179.

Marchegiani F, Marra M, Spazzafumo L, James RW, Boem M, Olivieri F, Cardelli M, Cavallone L, Bonfigli AR, Franceschi C. 2006. Paraoxonase activity and genotype predispose to successful aging. J Gerontol A Biol Sci Med Sci 61: $541-546$.

Martin GM. 2005. Genetic modulation of senescent phenotypes in Homo sapiens. Cell 120: 523-532.

Martin-Montalvo A, Mercken EM, Mitchell SJ, Palacios HH, Mote PL, Scheibye-Knudsen M, Gomes AP, Ward TM, Minor RK, Blouin MJ, et al. 2013. Metformin improves healthspan and lifespan in mice. Nat Commun 4: 2192.

Mecocci P, Polidori MC, Troiano L, Cherubini A, Cecchetti R, Pini G, Straatman M, Monti D, Stahl W, Sies H, et al. 2000. Plasma antioxidants and longevity: A study on healthy centenarians. Free Radic Biol Med 28: 1243-1248.

Milman S, Atzmon G, Huffman DM, Wan J, Crandall JP Cohen P, Barzilai N. 2014. Low insulin-like growth factor1 level predicts survival in humans with exceptional longevity. Aging Cell 13: 769-771.

Monami M, Colombi C, Balzi D, Dicembrini I, Giannini S, Melani C, Vitale V, Romano D, Barchielli A, Marchionni $\mathrm{N}$, et al. 2011. Metformin and cancer occurrence in insulin-treated type 2 diabetic patients. Diabetes Care 34: $129-131$.

Monsalve M, Olmos Y. 2011. The complex biology of FOXO. Curr Drug Targets 12: 1322-1350.

Muzumdar RH, Huffman DM, Atzmon G, Buettner C, Cobb LJ, Fishman S, Budagov T, Cui L, Einstein FH, Poduval A, et al. 2009. Humanin: A novel central regulator of peripheral insulin action. PLoS ONE 4: e6334.

Nebel A, Kleindorp R, Caliebe A, Nothnagel M, Blanche H, Junge $\mathrm{O}$, Wittig $\mathrm{M}$, Ellinghaus $\mathrm{D}$, Flachsbart F, Wichmann HE, et al. 2011. A genome-wide association study confirms APOE as the major gene influencing survival in long-lived individuals. Mech Ageing Dev 132: 324-330.

Pawlikowska L, Hu D, Huntsman S, Sung A, Chu C, Chen J, Joyner AH, Schork NJ, Hsueh WC, Reiner AP, et al. 2009. Association of common genetic variation in the insulin/ IGF1 signaling pathway with human longevity. Aging Cell 8: $460-472$.
Perls TT, Bubrick E, Wager CG, Vijg J, Kruglyak L. 1998. Siblings of centenarians live longer. Lancet 351: 1560.

Perls TT, Wilmoth J, Levenson R, Drinkwater M, Cohen M, Bogan H, Joyce E, Brewster S, Kunkel L, Puca A. 2002. Life-long sustained mortality advantage of siblings of centenarians. Proc Natl Acad Sci 99: 8442-8447.

Pollin TI, Damcott CM, Shen H, Ott SH, Shelton J, Horenstein RB, Post W, McLenithan JC, Bielak LF, Peyser PA, et al. 2008. A null mutation in human APOC3 confers a favorable plasma lipid profile and apparent cardioprotection. Science 322: 1702-1705.

Quinn BJ, Dallos M, Kitagawa H, Kunnumakkara AB, Memmott RM, Hollander MC, Gills JJ, Dennis PA. 2013. Inhibition of lung tumorigenesis by metformin is associated with decreased plasma IGF-I and diminished receptor tyrosine kinase signaling. Cancer Prev Res (Phila) 6: 801810.

Rajpathak SN, Liu Y, Ben-David O, Reddy S, Atzmon G, Crandall J, Barzilai N. 2011. Lifestyle factors of people with exceptional longevity. J Am Geriatr Soc 59: 1509_ 1512.

Rea IM, McKeown PP, McMaster D, Young IS, Patterson C, Savage MJ, Belton C, Marchegiani F, Olivieri F, Bonafe M, et al. 2004. Paraoxonase polymorphisms PON1 192 and 55 and longevity in Italian centenarians and Irish nonagenarians. A pooled analysis. Exp Gerontol 39: 629-635.

Roumie CL, Hung AM, Greevy RA, Grijalva CG, Liu X, Murff HJ, Elasy TA, Griffin MR. 2012. Comparative effectiveness of sulfonylurea and metformin monotherapy on cardiovascular events in type 2 diabetes mellitus: A cohort study. Ann Intern Med 157: 601-610.

Rozing MP, Houwing-Duistermaat JJ, Slagboom PE, Beekman M, Frolich M, de Craen AJ, Westendorp RG, van Heemst D. 2010. Familial longevity is associated with decreased thyroid function. J Clin Endocrinol Metab 95: 4979-4984.

Salani B, Maffioli S, Hamoudane M, Parodi A, Ravera S, Passalacqua M, Alama A, Nhiri M, Cordera R, Maggi D. 2012. Caveolin-1 is essential for metformin inhibitory effect on IGF1 action in non-small-cell lung cancer cells. FASEB J 26: 788-798.

Samaras TT, Elrick H. 2002. Height, body size, and longevity: Is smaller better for the human body? West J Med 176: 206-208.

Sanders AE, Wang C, Katz M, Derby CA, Barzilai N, Ozelius L, Lipton RB. 2010. Association of a functional polymorphism in the cholesteryl ester transfer protein (CETP) gene with memory decline and incidence of dementia. JAMA 303: 150-158.

Sandhu MS, Heald AH, Gibson JM, Cruickshank JK, Dunger DB, Wareham NJ. 2002. Circulating concentrations of insulin-like growth factor-I and development of glucose intolerance: A prospective observational study. Lancet 359: 1740-1745.

Schoenmaker M, de Craen AJ, de Meijer PH, Beekman M, Blauw GJ, Slagboom PE, Westendorp RG. 2006. Evidence of genetic enrichment for exceptional survival using a family approach: The Leiden Longevity Study. Eur J Hum Genet 14: 79-84.

Sebastiani P, Solovieff N, Dewan AT, Walsh KM, Puca A, Hartley SW, Melista E, Andersen S, Dworkis DA, Wilk 
JB, et al. 2012. Genetic signatures of exceptional longevity in humans. PLoS ONE 7: e29848.

Sebastiani P, Sun FX, Andersen SL, Lee JH, Wojczynski MK, Sanders JL, Yashin A, Newman AB, Perls TT. 2013. Families enriched for exceptional longevity also have increased health-span: Findings from the Long Life Family Study. Front Public Health 1: 38.

Seibel SA, Chou KH, Capp E, Spritzer PM, von Eye Corleta H. 2008. Effect of metformin on IGF-1 and IGFBP-1 levels in obese patients with polycystic ovary syndrome. Eur J Obstet Gynecol Reprod Biol 138: 122-124.

Smith DL Jr, Elam CF Jr., Mattison JA, Lane MA, Roth GS, Ingram DK, Allison DB. 2010. Metformin supplementation and life span in Fischer-344 rats. J Gerontol A Biol Sci Med Sci 65: 468-474.

Suh Y, Atzmon G, Cho MO, Hwang D, Liu B, Leahy DJ, Barzilai N, Cohen P. 2008. Functionally significant insulin-like growth factor I receptor mutations in centenarians. Proc Natl Acad Sci 105: 3438-3442.

Tabatabaie V, Surks MI. 2013. The aging thyroid. Curr Opin Endocrinol Diabetes Obes 20: 455-459.

Tan Q, Christiansen L, Bathum L, Li S, Kruse TA, Christensen K. 2006. Genetic association analysis of human longevity in cohort studies of elderly subjects: An example of the PON1 gene in the Danish 1905 birth cohort. Genetics 172: $1821-1828$.

Tazearslan C, Huang J, Barzilai N, Suh Y. 2011. Impaired IGF1R signaling in cells expressing longevity-associated human IGF1R alleles. Aging Cell 10: 551-554.
Mechanisms for Exceptional Longevity in Humans

Tosca L, Rame C, Chabrolle C, Tesseraud S, Dupont J. 2010. Metformin decreases IGF1-induced cell proliferation and protein synthesis through AMP-activated protein kinase in cultured bovine granulosa cells. Reproduction 139: 409-418.

Tseng CH. 2012. Diabetes, metformin use, and colon cancer: A population-based cohort study in Taiwan. Eur J Endocrinol 167: 409-416.

Van Heemst D, Beekman M, Mooijaart SP, Heijmans BT, Brandt BW, Zwaan BJ, Slagboom PE, Westendorp RG. 2005. Reduced insulin/IGF-1 signalling and human longevity. Aging Cell 4: 79-85.

Vergani C, Lucchi T, Caloni M, Ceconi I, Calabresi C, Scurati S, Arosio B. 2006. I405V polymorphism of the cholesteryl ester transfer protein (CETP) gene in young and very old people. Arch Gerontol Geriatr 43: 213-221.

Westendorp RG, van Heemst D, Rozing MP, Frolich M, Mooijaart SP, Blauw GJ, Beekman M, Heijmans BT, de Craen AJ, Slagboom PE. 2009. Nonagenarian siblings and their offspring display lower risk of mortality and morbidity than sporadic nonagenarians: The Leiden longevity study. J Am Geriatr Soc 57: 1634-1637.

Whittington HJ, Hall AR, McLaughlin CP, Hausenloy DJ, Yellon DM, Mocanu MM. 2013. Chronic metformin associated cardioprotection against infarction: Not just a glucose lowering phenomenon. Cardiovasc Drugs Ther 27: 5-16. 


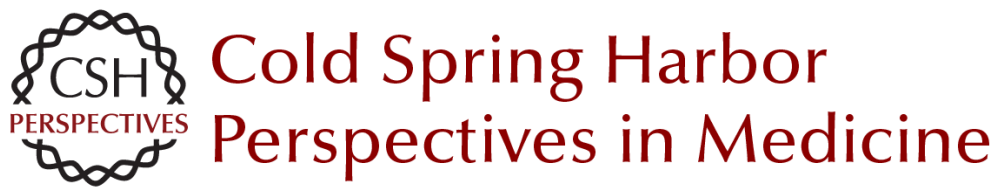

\section{Dissecting the Mechanisms Underlying Unusually Successful Human Health Span and Life Span}

Sofiya Milman and Nir Barzilai

Cold Spring Harb Perspect Med 2016; doi: 10.1101/cshperspect.a025098 originally published online December 4, 2015

\section{Subject Collection Aging}

\section{Personalized Financial Planning Using Applied \\ Genetics \\ S. Jay Olshansky, Bradley Willcox, Kirk Ashburn, et al.}

Biological Restraints on Indefinite Survival Jan Vijg and Steven N. Austad

The Role of the National Institute on Aging in the Development of the Field of Geroscience Felipe Sierra and Ronald A. Kohanski

The Funding Channels of Geroscience Stephanie Lederman

\section{Evolutionary Approaches in Aging Research Melissa Emery Thompson}

Interventions for Human Frailty: Physical Activity as a Model Linda P. Fried

How Research on Human Progeroid and Antigeroid Syndromes Can Contribute to the Longevity Dividend Initiative

Fuki M. Hisama, Junko Oshima and George M. Martin

Articulating the Case for the Longevity Dividend S. Jay Olshansky

\section{Funding Life-Extension Research Mehmood Khan}
Influence of Aging Science on Global Wealth
Management Michael Hodin

International Gains to Achieving Healthy

Longevity Andrew Scott, Julian Ashwin, Martin Ellison, et al.

From Life Span to Health Span: Declaring

"Victory" in the Pursuit of Human Longevity S. Jay Olshansky

Crowdfunding and Crowdsourcing of Aging

Science

Keith Comito

Inhibition of the Mechanistic Target of Rapamycin (mTOR) -Rapamycin and Beyond

Dudley W. Lamming

The Emergence of Geroscience as an

Interdisciplinary Approach to the Enhancement of

Health Span and Life Span

Felipe Sierra

The Economic Promise of Delayed Aging Dana Goldman

For additional articles in this collection, see http://perspectivesinmedicine.cshlp.org/cgi/collection/ 